\title{
ARTICLES
}

Journal of the Philosophy of Sport, 2006, 33, 125-143

(C) 2006 International Association for the Philosophy of Sport

\section{A Sporting Dilemma and Its Jurisprudence}

\section{Patrick Lenta and Simon Beck}

Our purpose in this article is to draw attention to a connection that obtains between two dilemmas from two separate spheres: sports and the law. It is our contention that umpires in the game of cricket may face a dilemma that is similar to a dilemma confronted by legal decision makers and that comparing the nature of the dilemmas, and the arguments advanced to solve them, will serve to advance our understanding of both the law and games. In asserting the existence of an illuminating intersection between a game and the law, we follow arguably the two preeminent legal philosophers of the last hundred years, H.L.A. Hart and Ronald Dworkin (12: pp. 34, 40, 59, 142-144; 5: pp. 101-104). Yet the proposition that that we can examine the dilemmas arising in one of these spheres to achieve a fuller understanding of what is at stake in the dilemmas encountered in the other does not command universal assent. According to Judith Shklar,

law and legal systems are not games but social institutions, and they do not exist in the social vacuum of a game ... The behaviour of men involved in social conflicts and the conditions under which these may, and may not, be resolved by appeals to rules simply do not resemble games. . . No system of law or morality known to history ha[s] such a simple inner consistency and symmetry. . . . Unlike games [legal systems] cannot be isolated, nor do they have simple purposes, a clear beginning, or an end. (22: pp. 105-106)

While Shklar is correct that legal systems are generally more complex than games like cricket (which Hart in particular regarded as bearing an illuminating resemblance to law), her assumption that games and the law shed no light on each other seems unfounded. Games and the law have much in common. Both are regulated by rules, deviation from which attracts criticism. In fact, the rules of cricket (unlike those of other games) go by the title of "laws." Like the legal system, complex games contain rules of different types: Some prohibit and penalize certain conduct (rules of criminal law, rules against fouling or disrespect to the umpire); other rules define the jurisdiction of the decision makers and other officials; still others specify what must be done for participants to prevail. In both games and law, challenged behavior is usually justified by reference to the rules. In both cases an

Lenta<lentap@ukzn.ac.za> and Beck<beck@ukzn.ac.za> are with the School of Philosophy and Ethics, University of Kwazulu-Natal, Private Bag X01, Scottsville, Pietermaritzburg, 3209, South Africa. 
appointed authority makes final authoritative decisions concerning the application of the rules (judges in the law, umpires in cricket, referees in chess and football). And in both cases there are risks attached to vesting in decision makers the power to apply the rules: There is always the possibility of error, bias, and corruption.

Shklar is also mistaken to assume that games necessarily have a "simple inner consistency." It is possible to imagine a game in which rules conflict. Moreover, as in law, cases may arise in which the application of rules could lead to irrational, absurd, or unjust consequences. The Umpire's Dilemma (henceforth UD) articulated by Colin Radford (16) and the subject of this article, is of this nature.

\section{The Umpire's Dilemma}

The UD arises in the case of applying the laws of cricket in particular circumstances. Describing it requires some background concerning those laws. The laws set out ten ways in which the fielding side can achieve their aim of getting one of the opposing batsmen out-two of those are involved in the dilemma. What are also involved are laws that relate to the umpire himself. Like the referee in other sports, the umpire is required to make decisions as to when rules apply or are transgressed. The laws of cricket give the umpire a special status, however-for they specify that a batsman is not out unless the umpire is certain that the relevant law applies or has been transgressed. ${ }^{2}$ In this way, the mind of the official enters into the game in a way that is peculiar to this game.

The laws are explicit on this point, and one specific law (backed, as Radford points out, by a long tradition) spells out that if there is any doubt in the mind of the umpire, the benefit of that doubt must be given to the batsman. This law has changed its place in the law book, but its substance has not changed over the years. Law 27.6 of the 2000 code reads as follows:

If an umpire is doubtful about any point that the other umpire may have been in a better position to see, he shall consult the latter on this point of fact and shall then give his decision. If, after consultation, there is still doubt remaining the decision shall be Not out. (15: p. 125)

Now we move to the relevant laws concerning the batsman that will feature in the dilemma. One is the law regarding being "out Caught." Should the umpire be certain that the ball is caught by a fielder once it comes off the bat without touching the ground in between, then the umpire is to decide that the batsman is out. The other is the law for "out Leg Before Wicket," or "LBW." This is a more complex law; disregarding a few sophistications that will not concern our case, it states that the umpire is to rule the batsman out if he is certain that the ball struck the batsman on his leg (or any other part of his body) on the way to hitting the stumps, the leg in effect preventing the ball from doing so. One provision that is important is that the batsman is not to be given out LBW if the ball was hit by the bat before striking the batsman's leg; that is, for a batsman to be out LBW, the umpire must be certain that the batsman did not hit the ball before he was struck on the leg.

With all that in place, we are in a position to describe the UD. Consider the following course of events in a game of cricket. The umpire sees the ball strike the batsman on the batsman's leg such that it would have gone on to hit the stumps had 
the leg not been in the way. The umpire is certain of all this, and had this been all that had occurred, he would have no hesitation in ruling the batsman out LBW. After striking the batsman's leg, the ball carries to the wicketkeeper without touching the ground and is caught. The umpire is certain of that as well. The only relevant doubt in the umpire's mind is whether or not the ball touched the bat just before striking the batsman on the leg. This doubt is important, however. Because he is not certain that the ball did not hit the bat first, he cannot give the batsman out LBW. If the ball did indeed hit the bat first, then the batsman would have transgressed the rule for out Caught, but since the umpire is not certain that it hit the bat, he cannot give the batsman out under that law. He is certain that the batsman has transgressed a law - if it is not the LBW law, then it is the Caught one, and if it is not the Caught law, then it is the LBW one. Despite this, it seems that the umpire cannot give the batsman out and must leave him to play on.

Thus the umpire faces his dilemma. It meets the requirements for being a dilemma in that there are only two options, ${ }^{3}$ each of which appears to have equally undesirable consequences. Our umpire has only two options-either to leave the batsman in or to give him out. There is no other option, so the dilemma cannot be dissolved as a false one in that way; if he simply does nothing rather than say the batsman is out or not out, then he effectively opts for not out. And at least on the face of things, the dilemma cannot be resolved by the undesirability of the one option obviously outweighing that of the other. If he leaves the batsman in, he makes a decision that is decidedly unfair as far as the fielding side is concerned. They have successfully induced the batsman to transgress a law, and the umpire knows this, yet he is acting as if they have not.

If the umpire acts fairly toward the fielding side and gives the batsman out, then he himself transgresses the laws - the very laws that it is his duty as official to see followed. Although the umpire is certain that a law has been broken, he is not certain which one. The law is unambiguous in requiring that any doubt whatsoever must count in the batsman's favor; the umpire has doubt as to how the batsman is out, and so the law requires the batsman to benefit from this: "If . . . there is still doubt remaining the decision shall be Not out" (15: p. 125).

Before we look more closely at what is at stake in each of these options, it might help to pay some attention to ways in which it may seem that the dilemma can be easily resolved. It may occur to you that the umpire could simply pronounce "Out!" and leave the method of dismissal unstated, thus avoiding either unfairness or breaking the law himself. The umpire is, however, required to specify which law it was that was transgressed - and a batsman can only be out Caught or be out LBW. There is not allowance in the laws for disjunctive dismissals - you cannot be out "Caught-or-LBW." The individual laws describing how you can be out are exclusive and exhaustive. There is also no room in the scenario outlined for arguing that the one form of dismissal is more likely than the other or that one should be a prior consideration to the other. As things occur in the description, the first relevant event is the ball touching (or not touching) the bat. That the umpire is not certain at this point that it did not hit the bat does not amount to a decision or commitment that it did not hit the bat, and so this does not weigh in favor of an LBW decision. An argument that the one law is more probably transgressed than the other in this instance has no foundation in the case as described. There is doubt in the case of both laws (any doubt is enough, and on top of that it is not as if the fact in question 
is different in the case of each law), and whether either applies turns on the same point (whether or not the ball hit the bat).

There is perhaps an even more obvious solution that might be put forward. The game of cricket has seen increasing use of technology to aid decisions, an aspect unknown when Radford devised the dilemma. Surely, you might ask, the obvious thing to do is for the umpire to appeal to the third umpire, who, with the aid of slow-motion replays and a "snickometer," can gain access to the fact that eludes our umpire. But two points rule out this avenue. The first is the technical one that the laws as they stand do not make allowance for umpires to be assisted on whether or not a ball hit the bat at any stage - they can only be assisted on whether the ball hit the ground before being caught (or on whether a run out or stumping was successful), and that is not in doubt here. The second point is that even if this technical point were removed, the dilemma can be recreated by a simple redescription in which the third umpire is unable to ascertain even with technology whether or not the ball hit the bat. The UD remains unresolved.

In his description of the dilemma, Radford argues that it may reflect a difference in metaphysical opinion, but we will not concern ourselves here with the UD's implications for metaphysics. Instead we identify possible solutions to the UD by capitalizing on similarities between the UD and a similar dilemma facing judges. It sometimes happens in the course of legal decision making that a judge is confronted by a rule of law the application of which would lead to absurd or unjust consequences. In such a case, the judge must decide whether to apply the rule, notwithstanding such consequences, or whether to depart from the literal meaning of the rule in order that the absurdity or injustice be reduced or removed. This dilemma, which Joel Feinberg refers to as the dilemma of judges who must interpret immoral laws (9), has traditionally been thought to divide the two main camps in legal philosophy, the natural lawyers and the positivists. ${ }^{4}$ Positivists tend to emphasize the benefits of formalism even when following a rule might produce substantive injustice. ${ }^{5}$ Natural lawyers have tended to deny the legal validity of rules that produce consequences inconsistent with the dictates of natural law. For natural lawyers such rules do not generate a duty on the part of judges to apply them.

What we will do here is contrast solutions to the judicial dilemma proposed by legal positivists - Frederick Schauer and H.L.A. Hart, in particular-and by the antipositivist Ronald Dworkin. We do so with two aims in mind. The first is to transpose contending solutions from the judicial arena into the domain of cricket as possible solutions to the UD. Second, we believe that applying the approaches of positivists and Dworkin to the UD brings into relief what is at stake in the disagreement between them in relation to the dilemma of judges who must interpret immoral laws.

We acknowledge that a task that in certain respects resembles the one we propose to undertake has been carried out in the pages of this journal. J.S. Russell has argued forcefully that Dworkin's approach should be followed in a case in some ways similar to that of the UD $(18 ; 17) .{ }^{6}$ Like Russell, we shall seek to determine whether Dworkin's approach can lead us to a satisfactory resolution of the UD. Thereafter our aim diverges from Russell's, however, since we also seek to show that legal positivists offer an alternative solution to the UD. Moreover, we believe that Russell is insufficiently explicit about the costs involved when the literal interpretation of the rules of games is departed from in order to avoid unjust or 
preposterous results. We emphasize, as a corrective, the costs incurred by departing from rules when such rules are linguistically clear and determinate, even if these costs should, in certain circumstances, be borne. We shall also argue that certain features of the UD that are not features of the examples adduced by Russell pose an obstacle to resolving the UD in the manner recommended by Dworkin (and Russell). The UD is different from Russell's most closely approximate example (the "Pine Tar Incident"; 18: p. 30) because in that case the "just" solution follows unproblematically once the rule is departed from in order to reach a just outcome. In the case of the UD, other rules present an obstacle to the just solution.

\section{Decision Making by the Rules}

Orthodox natural lawyers follow Cicero, Augustine, or Aquinas in adhering to some version of the doctrine lex iniusta non est lex (an unjust law is no law at all). Natural lawyers hold that judges do not have to violate their duty of fidelity to the law when faced with a substantively unjust law, since there is no duty on the part of the judge to apply it. In the circumstances of the UD, the natural lawyer might well argue that the umpire should ignore what the laws say and simply give the batsman out. There are two immediate difficulties with this position. Being a natural lawyer may be difficult to reconcile with being a judge or an umpire, since both are normally required to undertake to uphold the laws of the legal system rather than justice. A natural lawyer could not with a straight face swear to uphold the laws of a legal system, since in cases where law and justice conflict a natural lawyer is duty bound not to uphold an unjust law. A second difficulty is that natural lawyers seem to undervalue rules and rule-based decision making. We now turn to rule-based decision making and the values promoted by it. In the context of solving the UD, we are in effect starting to investigate just how grave the consequences are for the umpire's not following the laws and deciding that the batsman is out.

Since rules are general rather than particular, in certain cases the substantive justification for the rule and the consequences produced by the rule are at odds. Rules, that is, are suboptimal: A rule will sometimes produce outcomes inferior to those indicated by the direct application of its substantive justification or purpose (20: p. 100). The UD is an example of this. The rule that the umpire must give the batsman "Not out" if he is unsure whether the ball touched the bat is a substantively skewed accommodation to epistemic uncertainty. But this accommodation is purchased at the price of an absurdity in one particular (and rare) case: the circumstances of the UD. The rules setting out the circumstances in which the batsman is out Caught and out LBW, when read with the rule dealing with umpire uncertainty, seem to encompass the state of affairs in the UD. But the consequence produced by applying the rules - the umpire giving the batsman "Not out" when we (and he) know him to be out one way or another-exceeds the justification behind the rules, which is, presumably, to distinguish clearly between the possible ways of being out and to ensure that the batsman is out in one of these ways. The absurd or unjust consequence generated by the rules in the circumstances of the UD is a result of the overinclusivity of the rules' factual predicates (that part of a rule that can be formulated as "if $x$," where $x$ is a descriptive statement the truth of which is a necessary and sufficient condition for the applicability of the rule; 20: p. 23). 
The absurdity in the UD is not simply that the umpire is required to give the batsman "Not out" even though he must be out. Law 27.1 makes this distinction in the case where the batsman is out but the fielding side has failed to appeal: In these circumstances the batsman must be given "Not out" even though he is "in fact" out. In the latter case, we do not think it absurd or unjust for the batsman to be given "Not out" in the absence of an appeal, because there is a discernable purpose promoted by the rule: to require the fielding side to appeal to the umpire (in a way not dissimilar to a plaintiff petitioning a judge). Behind the rules requiring the umpire to give the batsman "Not out" in the UD, however, no such goal or purpose is discernable. Instead, the UD is an instance of what Hart terms an "unenvisaged case" (12: p. 129): The circumstances of the UD were not foreseen by the rule makers, who, if they had foreseen it, would presumably not have intended that it be resolved unfairly. ${ }^{7}$

Are there reasons for applying the rule in cases like the UD, notwithstanding the suboptimal outcome? In law, judges swear to apply the valid rules of the legal system. This is the judges' duty and it is a moral duty by virtue of their promise. Umpires are not required to make a similar undertaking to uphold, rather than depart from, the laws of cricket and therefore do not accrue the pro tanto moral obligation that arises from the act of promising. Nevertheless, a duty is imposed on umpires by the laws themselves. Law 3.6 spells it out: "The umpires shall satisfy themselves that ... the conduct of the game is strictly in accordance with the Laws" (15: p. 25). Moreover, there are important reasons for having rules and rule-based decision making.

The first reason for valuing rule-based decision making is that it promotes reliance or certainty. Rules enable those affected to predict in advance what the decision maker is likely to decide. This reason applies to the fielders rather than the batsman in the UD because the batsman can do nothing to ensure that his act falls within the factual predicate of the "out Caught" and "out LBW" rules in conjunction with the "umpire uncertainty" rule. When the UD arises, it is not because it has been deliberately brought about by the batsman. Nevertheless, reliance by those affected is an important reason to value rules in most cases. Second, rulebased decision making promotes efficiency in that it frees the decision maker from the responsibility of determining whether in every case the outcome is consistent with the rule's justification. This reduces the possibility of error resulting from a particularistic decision, including miscalculation, confusion, or bias on the part of the decision maker.

Reasons of reliance and efficiency are utilitarian reasons for expressing a justification as a rule. There is a third, nonutilitarian reason for rule-based decision making relating to allocation of power. Rules withdraw decisional jurisdiction from certain classes of decision maker, on the basis that certain officials should have exclusive jurisdiction to make some decisions and other officials should exclusively be empowered to make other decisions. In law, the doctrine of separation of powers mandates that the legislature, as an accountable and representative institution, should make law, while judges should restrict themselves to applying it. In cricket, it might similarly be argued that rule making (and rule changing) should be left to the legitimate administrative body entrusted by the cricketing community with this task, while umpires should simply apply the rules. 
Someone might respond to this argument that it does not matter who makes decisions, provided the right decisions are made. There are, however, moral and political reasons for reserving decision making on certain questions to certain authorities. In politics one such reason is democratic legitimacy, as Jeremy Waldron suggests in his argument against Dworkin's advocacy of rights-based judicial review (26: pp. 292-294). Waldron gives as an example a dispute about some aspect of the electoral system in which the United Kingdom is embroiled. He asks us to imagine that the queen, in a moment of exasperation with the inability of politicians to resolve this issue, declares that from a certain date onward the electoral system will be arranged in a particular way. Suppose for the sake of argument that the queen's decision is the right one. In such a case citizens could reasonably object, notwithstanding that her decision is right, that the queen has usurped a decision that should properly have been made by the people. The point is that there is something lost when individuals or institutions lacking the requisite legitimacy make certain decisions. If the right decision is made, there may be something to set against this loss. But there is still a loss. Whereas if the legitimate institution gets the decision wrong, we can at least comfort ourselves that the legitimate institution made the decision.

We think that the issues of efficiency and allocation of power are good (though not necessarily overriding) reasons for restricting the exercise of discretion by umpires. Russell, it would seem, disagrees. He argues that the fact that

solutions to the hard cases we have examined will be readily apparent to most observers with a passing familiarity with a relatively complex sport like baseball suggests that the exercise of discretion should be within the competence of most reasonably well-trained umpires. (18: p. 44)

As a result, "there is no plausible prospect of umpires hijacking the game" (18: p. 34). As things currently stand, there is no rule that obligates umpires in cricket to receive training or be experienced beyond their being familiar with the rules of cricket. But even if there were such a requirement, judgments of experienced and trained umpires would still be susceptible to the distortions of myopia, bias, and corruption. Moreover, Russell's defense of the umpire's exercise of discretion is not a convincing reply to the argument we have made about allocation of power: There may be good political and moral reasons for saying that umpires should restrict themselves to applying clear and unambiguous rules and leaving decisions about rule making and rule changing to cricket's governing body. It is also the case that people notoriously disagree about what justice requires. By permitting judges to depart from the literal interpretation of rules when it offends their sense of fairness or justice, we may be licensing judges in certain cases to impose their controversial views on the game. It may be that in some cases, the Pine Tar Incident, for example, or the UD, the just outcome will be uncontroversial. But in other cases, there may be significant disagreement about what justice or fairness requires. Russell responds to this point as follows: "Where solutions to problems are not relatively clear, it is to be expected that well-trained umpires, like municipal judges, will exercise restraint" (18: p. 44). This is simply too optimistic. Even well-trained umpires may in less clear-cut cases be wrong about whether there is a clear solution to a problem and may fail to demonstrate appropriate restraint. The same applies to municipal judges. 
One final reason for sticking to the rules, related to the value of reliance, is that it promotes fairness in the sense of treating all individuals in the same way, if not in the sense in which the umpire's leaving the batsman in might be seen as unfair to the fielding side. Hart sees this as an essential element of justice:

If we attach to a legal system the minimum meaning that it must consist of general rules - general both in the sense that they refer to courses of action, not single actions, and to multiplicities of men, not single individuals - this meaning connotes the principle of treating like cases alike, although the criteria of when cases are alike will be, so far, only the general elements specified in the rules. It is, however, true that one essential element of justice is the principle of treating like cases alike. This is justice in the administration of law, not justice of the law. (11: pp. 623-624)

All of these reasons add weight to one side of the dilemma. Their combined effect shows clearly that should the umpire decide to leave the batsman in, it need not simply be a matter of slavish legalism or rule worship.

\section{A Hard Case? Dworkin}

Having canvassed the reasons in favor of rule following, we turn to the question of whether the elimination of unjust or absurd consequences requires a departure from the rules. The distinction between "hard" and "easy" cases serves to introduce this topic. In legal philosophy, "hard cases" are usually defined as cases in which the language of the applicable rule does not settle the question of what the decision maker's decision should be because its wording is vague or indeterminate. "Easy cases" are cases in which the wording of a rule clearly directs a particular outcome. The most famous example of a hard case is adduced by Hart: a rule that forbids vehicles in the park. This rule clearly forbids an automobile, Hart thinks, but what about roller skates and toy cars? Hart argues that general words such as "vehicle" have a core of settled meaning (if vehicles are anything they include automobiles) and a penumbra of uncertainty (are roller skates and toy cars vehicles?). In such cases, when the rule is susceptible to multiple interpretations, positivists think that the judge should exercise his discretion by legislating. That is, the judge should choose between possible interpretations of the rule the one that will give effect to what the judge regards as good policy (11: pp. 606-615). Hart condemns as formalism the denial or downplaying of the necessity for choice in these circumstances (12: p. 129).

From the positivist perspective, the UD does not appear to be a hard case. The rules are neither vague nor indeterminate; their plain language clearly mandates a result. The UD is a hard case in a different sense: The result generated is, because of its absurdity or moral injustice, "hard to swallow" (20: p. 210). Legal positivists insist that judges have a pro tanto duty to apply the law in easy cases, notwithstanding any absurdity that might result. In the same way, positivists are likely to insist that since the UD is not a hard case, the umpire has a pro tanto duty to apply the laws, notwithstanding the unreasonable consequences that ensue.

Is the Pine Tar Incident that Russell considers an easy or a hard case in this sense? In this baseball example, the umpire disallowed a home run on the grounds 
that tar resin had been applied to the bottom of the batter's bat. The rules clearly prohibited batters from applying sticky substances to their bats on pain of removal from the game; they mandated that a ball hit with such a bat is an illegally batted ball and that a batter is out if he hits an illegally batted ball. These rules seem sufficiently clear and determinate. As Russell puts it, "the logic of the rules seemed inescapable: Brett was out" (18: p. 30). As Russell observes, however, the result mandated by the rule was unjust because the batter had accrued no advantage from the resin on his bat. He deserved to be awarded the game-winning home run. The positivist's take on all of this will nevertheless be that the rules are clear and determinate.

Russell seems to imply that Hart would find the applicable rules in the UD and the Pine Tar Incident indeterminate (18: pp. 32-33). Indeterminacy, for Hart, refers to cases of doubtful application, such as the question of whether a toy car is a vehicle for the purposes of the rule prohibiting vehicles in the park. Hart observes that there will be "plain cases" in which "the general terms need no interpretation and where the recognition of instances seems unproblematic or "automatic". (12: p. 126). Thus, Hart notes that "if anything is a vehicle a motor-car is one." He adds that there will also be unclear cases, such as the question of whether a toy car is a vehicle. What Hart is not saying is that if the purpose of the same rule was to permit motor cars in the park, then "vehicle" in the rule does not refer to motor cars. To the contrary, those tasked with applying the rule will be applying the rule if they insist that motor vehicles are not permitted in the park. To hold otherwise is to deny that rules may point to results that diverge from those that a decision maker would have reached apart from the literal meaning of the rule. Similarly, notwithstanding that the application of the applicable rules in the circumstances of the UD may not have been foreseen in the circumstances of the UD and the Pine Tar Incident, it is hard to see how they could be considered indeterminate in anything like the way in which "vehicle" is indeterminate in relation to a toy car. If the rules in the Pine Tar Incident are vague or indeterminate in this way, Russell provides no evidence to show why this is so.

Dworkin argues that cases like the UD and the Pine Tar Incident can be "hard" because the acontextual interpretation of the words of the rule does not settle the question of what the "real" rule is (6: pp. 16-17). Although he thinks that judges have duty of fidelity to the law, Dworkin denies that they have a duty to apply the acontextual, or literal, meaning of the words of the rule in these circumstances (14: pp. 103-107). Judges must interpret rules "constructively" in the light of moral principles embedded in the law, which will ameliorate the unjust consequences that follow from the literal interpretation of the rule. A constructive interpretation imposes a purpose on a legal practice to show it in its best light (6: p. 52). If we follow Dworkin, the UD must be viewed as a hard case.

To elucidate Dworkin's argument more clearly, we turn to a case on which he relies heavily, Riggs v. Palmer (also known as "Elmer's case"). ${ }^{8}$ The facts of Riggs are as follows. A testator, Francis Palmer, left an inheritance to his grandson, Elmer. Concerned that his grandfather would alter the terms of the will to his disadvantage, Elmer murdered him. The court had to decide whether Elmer had a legal right to the inheritance. The applicable statute, the New York Statute of Wills, did not explicitly cover this case but simply provided that a person named in a validly executed will shall inherit on the death of the testator in accordance with its terms. Although the 
court split in Riggs, all of the judges agreed that in an acontextual interpretation the words in the statute were neither vague nor ambiguous (23: pp. 383-385). In his minority judgment in Riggs, Justice Gray argued for a literal interpretation of the statute on the basis that testators should know in advance how their wills are going to be treated; he prioritized predictability and certainty over the injustice of the consequences. According to the majority judgment of Justice Earl, which Dworkin endorses, it is absurd to suppose that the legislators intended the murderer of a testator to inherit, and therefore the statute, properly interpreted, did not have this consequence. The majority assumed that it was likely that the legislators did not have the case of the testator-murdering beneficiary in mind at all (just as, we are tempted to say, it is unlikely that cricket's rule-making body had the possibility of the circumstances of the UD in mind when it drafted the laws). Justice Earl argued that it was sensible to assume that the legislators had an intention to respect traditional principles of justice. He also held that a statute does not have any consequence that the legislators would have rejected had they considered it. The majority removed the unjust consequence following from the literal interpretation by appealing to the principle embedded in U.S. law that no person should profit from his own wrongdoing. Dworkin thinks that Riggs exemplifies his theory of constructive interpretation, in which courts resolve hard cases by appealing to (moral) principles embedded in the law. When the literal interpretation of the rule leads to an unjust consequence, the court should interpret the rule in the light of the purpose of the legal system as a whole (6: pp. 16-20, 45-86).

Dworkin takes an analogous approach to decision-making in games. Taking chess as an example, he notes that players commence play with an understanding that the rules of chess will apply. They tacitly consent to the enforcement of the rules and have a right to the enforcement of these rules and no others. Nonetheless, some rules will require interpretation or elaboration before the official can enforce them in hard cases (5: p. 102). In such cases, the referee must respect the character of the game. As Dworkin puts it, the hard case

asks what it is fair to suppose the players have done in consenting to the ... rule. The concept of the game's character is a conceptual device for framing that question. It ... internalizes the general justification of the institution. (5: pp. 104-105)

In asking what the players were consenting to when they consented to "play by the rules," the referee "may study the enterprise as a whole and not just the rules" (5: p. 105). When a rule leads to a particularly bad or absurd result, the judge should interpret the rule constructively in the light of the game as a whole (which is not, of course, to suggest that Dworkin thinks that judges should exercise "strong discretion," a practice that Dworkin explicitly repudiates).

Russell argues for the applicability of Dworkin's theory of legal decision making to sports in order to justify the departure by umpires from the literal interpretation of the rules when the interests of fairness or justice are promoted by doing so:

Umpires can legitimately use their authority to clarify and resolve ambiguities in rules, to add rules, and even at times to overturn or ignore certain rules 
and ... the exercise of discretion is governed by principles underlying the games themselves and by an ideal of the integrity of games. (18: p. 28)

If we follow Dworkin and Russell, the umpire in the UD is entitled to establish the purpose behind the rules. The umpire may well conclude that the purpose of the relevant rules was not to force him to give a player who must be out "Not out" and that the absurdity or injustice is produced by the failure of the rule makers to consider the unprecedented factual circumstances of the UD. He may also conclude that players do not consent antecedently to the acontextual interpretation of the rules being applied to the circumstances of the UD. The umpire is entitled, without violating his judicial duty, to have recourse to what he regards as the character of the game and may decide that the game as a whole is committed to a principle such as that set out by Russell: "Rules should be interpreted in such a manner that the excellences embodied in achieving the lusory goal of the game are not undermined but are maintained and fostered" (18: p. 35).

Since a literal interpretation of the rules would, because it would bestow on the batsman an "unearned gift" (18: p. 38), violate this principle (and perhaps also a substantive conception of the principle of justice or fairness, "treat like cases alike": The rules provide in other cases that when the fielders have appealed and the batsman must be out, the umpire should give him out), the rules, properly interpreted, do not have this consequence. Just as in Riggs the majority interpreted the rule to incorporate a tacit exception, so the Dworkinian umpire in the UD might well interpret the rules as tacitly incorporating the principle that if an umpire is certain that a batsman has transgressed one or other of the laws under which they would be out then they must be given out. In such a case, in Dworkin's approach, the umpire would not be departing from the rules, but interpreting them, because "it is a perfectly familiar speech practice not to include, even in quite specific instructions, all the qualifications one would accept or insist on: all the qualifications that 'go without saying"' (7: p. 1816). The important point about Dworkin's approach, as Schauer observes, is that "the plain meaning of the statutory words ... stand in something less than a one to one relationship to the outcome that the [decision maker] might reach without exceeding the bounds of professional respectability" (21: pp. 1305-1306). Moreover, in looking at the purpose behind the rule in the context of the character of the game as a whole, the umpire is in Dworkin's account doing his duty. He is not going beyond the law and deciding in the way morality requires.

In this way, Dworkin seems to have provided a neat solution both to a "hard" case like Riggs and to the UD. Russell's solution to his baseball dilemmas follows these lines - if the rules are interpreted as including reference to "the excellences embodied in achieving the lusory goal of the game," then those dilemmas can be dissolved. We nevertheless think it is worth pausing to consider whether the Dworkinian resolution to the UD is as satisfactory as it first appears. There is reason to believe that the UD is not as closely analogous to Riggs as it might at first appear to be, and the aspect in which they are disanalogous raises new problems. In the case of Riggs, once recourse is had to the tacit principle of a wrongdoer not profiting from his wrongdoing, the law provides the morally correct decision and the problem is solved. The same goes for Russell's dilemmas - even for the "Pine Tar Incident," which is unlike his others (but like the UD) in that the rules lead to a 
determinate but morally unjust decision. The position is more complex in the UD. Even when we introduce a tacit principle that transgressors must be given out, the laws of cricket still seem to present an obstacle to the umpire giving our batsman out, because the batsman cannot be ruled "out Caught" (since the umpire is not certain that the ball was hit) and he cannot be ruled out LBW (since the umpire is not certain that the ball was not hit before the leg was struck). Once the relevant rule is departed from in order to reach a just outcome, nothing in Riggs prevents Dworkin's interpretation of the law from leading to the morally right outcome; in the UD it would appear that the umpire cannot straightforwardly resolve this dilemma by having recourse to the relevant principle; the laws requiring the umpire to be sure not only that the batsman is out but also how he is out mean that the principle that transgressors must be given out is insufficient to resolve the UD, because the principle provides no help as to which way the umpire should decide that the batsman is out. According to the tacit principle, the umpire must give the batsman out, but he has no way of doing so in light of the laws regarding how a batsman can be given out.

Dworkin would likely respond that the very laws that together require the umpire to be sure in which way the batsman is out are those that require interpretation. Their literal interpretation may require that the umpire be sure that the batsman is "out Caught" or "out LBW" before he gives him out, but once we construe these laws as an expression of the intentions of a reasonable drafter, ${ }^{9}$ and once we notice that the relevant laws do not expressly override the principle that transgressors should be given out, it does not matter that the relevant principle does not guide the umpire in following the applicable rules because these rules are to be interpreted in the light of the relevant principle. Since the applicable rules are not intended to apply literally to the circumstances of the UD (because the ultimate purpose of the rules requiring that the umpire must be sure how that batsman was out is to ensure that a batsman clearly is out in accordance with at least one of the stipulated ways of being out) and since the UD was, it can reasonably be assumed, not foreseen, the true meaning of the relevant laws may be that an exception to the laws requiring (in this instance) that the umpire give the batsman out either out Caught or out LBW is necessarily implied. The implied exception might read as follows: Notwithstanding the provisions of any other laws, the umpire shall, if he is certain that the batsman is out either Caught or LBW, give the batsman out disjunctively, "out Caught-or-LBW." By interpreting the laws to contain this implied exception, the umpire construes them in conformity with a fundamental principle of cricket. By reconciling the rules with the relevant principle in this way, the umpire is doing what he believes a reasonable drafter, having the best interests of cricket at heart, would have done had he contemplated the circumstances of the UD.

Once again, it appears that there is a Dworkinian solution to the UD. But while we agree that the problem can be solved in this way, we think that there are costs incurred in this solution-costs that some might not be prepared to pay and, without being unreasonable, refuse to pay them. Some may find the insertion of an exception to enable to umpire to give the batsman out disjunctively a cause for consternation. They may object that in the Dworkinian solution above, it would appear that the umpire must invent and insert an additional rule into the rules in order to square the existing rules with the principle. Yet this additional rule does not seem to be contained within the principle in the same way as the rule that Elmer 
should not inherit is implicit in the principle that wrongdoers should not profit from their criminality. The concern is that there is currently no law permitting an umpire to give a batsman out disjunctively, nor is there anything like such a law. As noted in Section 2, the laws by which a batsman can be given out are exhaustive and exclusive; when there is the foreseen possibility that a batsman may have transgressed more than one law, the laws explicitly state under which law he is to be ruled out. For instance, Law 30.2 ("Bowled to take precedence") reads, "The striker is out Bowled if his wicket is put down as in 1 above, even though a decision against him for any other method of dismissal would be justified" (15: p. 133). In order to reach the fair result by Dworkinian interpretation, the umpire must add an exception to the existing laws of a kind that has no parallel or precedent in the laws - an exception of a kind that the laws expressly seek to avoid. The Dworkinian solution that we have outlined (and that is consistent with the solution Russell offers to his simpler dilemmas) requires the umpire to reach a decision on the best understanding of the game as a whole. The correct interpretation is the one that the reasonable and conscientious drafter of laws, having regard to the character of the game as a whole, would have approved. But it is by no means clear that the reasonable drafter would add the exception that the UD seems to require. The reasonable drafter might well agree that doubt as to how a batsman is out was not intended to prevent him being given out in the circumstances of the UD, but the reasonable drafter, with the character of the game and its laws in mind, might well pale at the proposed exception. In Riggs the specification of the principle by Judge Earl produced, in effect, a new rule or specific exception-but not one that was totally out of place in its context like this one is. Our contention, then, is that there is a Dworkinian solution to the UD, but one that comes at what might well be seen as too considerable a cost.

A positivist umpire will decline Dworkin's invitation to dissolve the UD by considering the character of the game and having recourse to the relevant principle. He will likely deny that a discrepancy between the literal meaning and the purpose behind the rules should be resolved in favor of the latter and hold that the Dworkinian umpire has abdicated his responsibility for interpreting the laws. The positivist umpire may well persist in thinking that the laws requiring the umpire to be sure in which of the ten ways the batsman is out are still operative and binding on him. In all likelihood, a positivist umpire will reason that the only way to resolve the UD is for the umpire to decide in accordance with what he regards as the dictates of morality. But if he follows his conscience and decides to give the batsman out, he still needs to overcome the problem of having to specify in what manner the batsman is out. In the next section we explore solutions to the UD that might be advanced by positivists.

\section{Duty Versus Conscience? Hart and Schauer}

The difference between Dworkin's approach and that of positivists such as Hart is that for Dworkin, when the umpire departs from the literal interpretation of the words of the statute to determine the purpose behind the rule, the umpire is nevertheless applying the rule, properly interpreted, and is not in violation of his 
duty of fidelity to the law. For Hart (and Schauer), however, by failing to give effect to the literal interpretation of the linguistically precise words of the statute, the umpire is departing from the rules: He is deciding according to the dictates of extralegal morality. Positivists like Hart (and Bentham and Austin before him) hold that valid laws, even if morally outrageous, are still valid laws, and the judge has a duty to apply them.

It is sometimes mistakenly imagined that positivists are committed to arguing that the judicial duty to apply determinate and valid rules is in all cases overriding. What positivists are committed to saying, as David Lyons observes, is that "if the meaning of the law is clear, determinate and uncontroversial, so that it offers sufficient guidance for official decision, then there is only one way to act within the law, which is by following the law's directions" (13: p. 87, emphasis added). Yet positivists need not be committed to the view that judges must always act within the law regardless of the unjust consequences produced by applying clear and determinate rules. Positivists do not insist that we have to live with absurd or preposterous consequences. When excessively unfair consequences could result from applying clear and determinate rules, positivists are likely to insist that umpires are justified in stepping outside the rules.

Positivists insist that when the meaning of the rule is clear, the decision maker faces a conflict between his duty of fidelity to law and his duty of fidelity to morality. The judge must decide between applying the rule despite the injustice or absurdity and doing what he thinks is morally correct. The judge, who has a pro tanto duty to uphold the law, has four options: Apply the law against his conscience, follow his conscience contrary to his duty of fidelity to the rules, lie, or resign (2: p. 6).

Since, for positivists, rule following promotes values independent of the consequences rules produce, the existence of a valid rule is always a reason for applying it. Rules promote fairness, certainty, and efficiency and disable officials from making certain decisions beyond their remit. To decide whether to depart from the rules and follow morality, it is necessary to weigh the cumulative force of these reasons against the seriousness of the injustice or absurdity produced by applying the rule. If the consequences are "laughably unreasonable and sadly unfair" (9: p. 6) there is a powerful, though not necessarily overriding, reason for not applying the rule. Most positivists believe that the rule should be followed, except in those instances in which the reason for having the rule is insufficient to overwhelm the reasons provided by the absurdity or injustice for departing from it. Balancing the relevant reasons in the UD, we must ask whether the consequences produced by the rule are sufficiently serious to warrant a departure from the rule. Schauer seems to indicate that the consequences are insufficiently serious when he observes that "legal systems deal with important matters in the way that the rule-system of chess and cricket do not" (21: p. 202). Robert Cover expresses this point in a more dramatic register:

Legal interpretation takes place in a field of pain and death. ... Legal interpretive acts signal and occasion the imposition of violence upon others. A judge articulates her understanding of a text, and as a result somebody loses his freedom, his property, even his life. (3: p. 1601) ${ }^{10}$

Nothing so serious turns on a game of cricket: This is presumably what Shklar means when she says that games exist in a social vacuum. 
On the other hand, the reasons we have considered in support of rule-based decision making - fairness, predictability, efficiency, and allocation of power-seem less important in cricket than in law. In law, rule-based decision making reduces the possibility of decision-maker error. We take errors seriously because the consequences of errors in law are grave. But to the extent that errors on the part of an umpire in a game of cricket result in less serious consequences, we should be less concerned about them. Similarly, the fact that the umpire uses his discretion in a way we normally think should be reserved for the rule-making body is less serious than when issues of principle and policy are removed from the political arena and placed in the hands of judges. Such decisions in law have significant social consequences, and the people's demand that they rather than a small group of judges should decide these matters should be taken seriously. By contrast, an objection to the umpire's exercise of discretion on the basis that it offends against the proper allocation of power is vulnerable to the riposte: "It's only a game!"

In the circumstances of the UD, the umpire, weighing the reasons for and against applying the rules, may decide that the benefits of rule following outweigh a single absurdity that is likely to arise only infrequently and conclude that the absurdity should be tolerated. If he does this, he can of course launch a campaign or lobby cricket's rule-making body. If he manages to attract the support of a large number of like-minded cricketers, his views have a good chance of prevailing. On the other hand, the umpire may decide that the absurd consequence generated by the rule is sufficiently serious to justify departing from the rule in order to remove the absurdity. The decision will be complex and difficult.

If, however, the umpire decides to give the batsman Out on the grounds that he is morally required to do so, he will run into the problem that he is expected to specify how the batsman is out. He may have to lie: In the circumstances of the UD he may have to say that he is certain either that the ball touched the bat or that it did not. Dworkin suggests that judges may be forced to lie in circumstances in which constructive interpretation is impossible because the legal system is despotic and wicked, that is, where the "character" of the legal system is evil and there are no applicable moral principles embedded in the law. In such legal systems, among which Dworkin includes that of apartheid South Africa, "it may be that [the judge] must lie because he cannot be of any help unless he is understood as saying, in his official role, that the legal rights are different from what he believes they are" (5: p. 327). But if the positivist umpire decides to lie and give the batsman out either out LBW or out Caught, he must resign himself to paying a moral price for removing the absurdity from the rules in this way, even if he is correct that it is the right thing to do, all things considered.

The final option facing the umpire is to resign, a course of action that at least one legal theorist recommended to apartheid judges (25: p. 266). This option has serious drawbacks. If the umpire's motivation is to protect his own integrity, what help does he give the victims of the absurdity by doing this? And if his intention is to register a protest publicly and spectacularly, it is likely that he will be replaced by someone more committed to applying the letter of the law in all cases. ${ }^{11}$ Under the laws of cricket as they stand, an umpire's resignation would not mean the end of the game, merely that he would be replaced. ${ }^{12}$ By resigning in protest the umpire would simply pass the dilemma on to his replacement and would in effect have made whatever decision the replacement makes. 


\section{Conclusion}

Our ambition in this essay has been to locate solutions to the UD in the jurisprudence of positivists and Dworkin, but also thereby to foreground the heart of the disagreement between positivists and Dworkinians in relation to the dilemma of judges who must interpret laws the literal interpretation of which would lead to absurd or unjust consequences. Positivists and Dworkinians are likely to agree that in the UD the umpire should give that batsman out. They are also likely to disagree about what the umpire is doing when he does so. It has not been our aim to adjudicate between these rival camps; our concern has been to contrast the Dworkinian approach, which appears to hold sway among the majority of philosophers of sport, with the positivist approach in order to show how they differ.

We have argued that Dworkin's approach seems to suggest that the umpire, by interpreting the rules properly, could regard them as containing a tacit exception to the rules in the circumstances of the UD. In this approach, the rules may be interpreted as incorporating an exception to the effect that the umpire may in the circumstances of the UD give the batsman out disjunctively: "out Caught-orLBW." We have contended that positivists are likely to find this resolution of the dilemma no resolution at all but rather a cheat inasmuch as it requires the judge to invent an exception that permits him to give the batsman out disjunctively out "Caught-or-LBW." Such an amendment to the rules, neither vague nor indeterminate, will be regarded as inconsistent with the judicial obligation of fidelity to the rules. Positivists are likely to insist that if the umpire decides that the judicial duty is outweighed by the moral requirement that the batsman should be given out, he will have to take the view that the applicable rules are defeasible in the service of morality. Positivists are likely to argue that if the umpire decides to forestall the repugnant result produced by applying the rules, he will probably have to lie and say that the batsman is out as directed by the rules; that is, the umpire will have to decide between saying that the batsman is out Caught or that he is out LBW, but he will have to choose one of these options and declare publicly the grounds on which the batsman was given out.

It is consistent with everything we have said so far that cricket would be improved were the rules changed so as to take the UD into account and mandate a fair result should it recur. ${ }^{13}$ There are at least two possibilities. One possibility is to amend Law 27.6, which currently specifies that the benefit of the doubt goes to the batsman, to the effect that that if the umpire is certain the batsman is out, but uncertain in which of two possible ways he is out, the umpire shall give the batsman out in one of the two ways, the selection of which way the batsman is to be given out to be at the umpire's discretion. Another possibility would be to permit the umpire to give the batsman out disjunctively. Neither positivists nor Dworkinians have reason to oppose this accommodation to the epistemic uncertainty of the UD should it recur. Positivists would doubtless prefer that judges not to be confronted by the choice between playing by the rules and deciding according to the dictates of morality. And although Dworkinians hold that the umpire may reach the right answer without having to go beyond the law, they would presumably concede that it would be better (and easier on the umpire) if the literal interpretation of the rule accorded with principle. 
In the end, resolving the UD comes down to two questions. First, is the absurdity or injustice generated by the rule sufficiently serious to overwhelm the values advanced by rule-based decision making? Is it, as Feinberg puts it, "flagrant, gross and outrageous injustice, and utterly crazy pointless unreasonableness" (9: p. 35)? We have argued that both positivists and Dworkinians should answer this question in the affirmative. Second, if the absurdity or injustice is of sufficient magnitude to justify the umpire's remedying it, is he thereby acting in accordance with his duty of fidelity to the laws, as Dworkinians are likely to insist, or is he, in doing what he thinks is morally required, violating his judicial duty in the service of morality, as the positivists would have it?

\section{Acknowledgment}

For helpful comments and suggestions, we are indebted to Trevor Allan, Nicholas Dixon, J.S. Russell, and two anonymous referees.

\section{Notes}

1. We will usually refer to them as "laws," but since much of the literature on games uses only the term "rules" we will sometimes use the terms interchangeably, hoping that this will not offend the cricketers.

2. We shall, for the sake of convenience, use the masculine form of the noun "batsman," the pronoun "he," and the possessive adjective "his" throughout, not to indicate that only men are umpires and play cricket - that would ignore the substantial contributions to the game by women as players and umpires. We use the masculine, rather than the feminine or neutral form, to avoid false gender neutrality: to signal, that is, that the vast majority of players and umpires are men.

3. In the section "Duty Versus Conscience? Hart and Schauer" we will discuss a possible third option, but we will argue there that it does not really affect the nature of the dilemma.

4. One might object that since the dilemma in the UD hinges on epistemic uncertainty, the legal dilemma we should be focusing on is not the dilemma of the judge who must apply unjust laws but rather the dilemma arising in cases in which (as in the UD) there is epistemic uncertainty. One might think that the analogous dilemma is the one arising in cases in which it is clear that one of two or more laws has been violated, but it is unclear which one. Consider the following example from criminal law. Suppose we know for certain that A had nonconsensual intercourse with B. The exact time of B's death, which occurred for reasons irrelevant to A's act-B had been rendered comatose from a lethal dose of poison administered by $\mathrm{C}$, say-is unknown. We do not know whether $\mathrm{A}$ is guilty of rape or corpse mutilation, assuming the latter to be a crime. To see why it would not be more helpful to focus on this dilemma rather than the dilemma of the judge who must apply unjust laws, consider that the relevant legal system will deal with the criminal dilemma in one of three possible ways. It may contain no rule applicable to this eventuality. If so, it is relevantly unlike the UD. Alternatively, it may contain a rule that resolves the dilemma by specifying that in the event that it is certain that one of two or more crimes was committed but uncertain which crime was committed, the accused will be found guilty of the lesser offence. This is certainly a useful rule, but there is no rule like it in cricket that is applicable to the UD. The third possibility is that there will be a legal rule that provides that in the event of uncertainty about which crime was committed, the accused must be found "not guilty" of any criminal wrongdoing. This is relevantly similar to the UD, but here the dilemma that confronts the judge will be the legal dilemma on which we focus - the dilemma of a judge who must apply an unjust law - the injustice being that an accused we know to have committed a crime will walk free. 
5. Whether positivists have anything to say in support of formalism depends, of course, on how formalism is defined. "Formalism" is used in one (pejorative) sense to refer to attempts to redescribe an interpretive choice as a compulsion. Sometimes the application of certain terms is contested because these terms - "liberty" and "equality," for example-are pervasively indeterminate. Every application of such terms requires that supplementary premises be added to apply them to specific cases. An application of these terms that denies the choice made among a range of supplementary premises is formalistic in this sense. In other cases, the indeterminacy is not pervasive but is instead located at the edges of the meaning of a particular term. According to Hart, legal terms possess a core of settled meaning and a penumbra of uncertainty. For Hart, formalism consists in the denial of choice in the penumbra of meaning. It is the unwillingness to concede in cases of doubtful application that choices must be made that extend into the realm of public policy (12: p. 129). We are not claiming that modern positivists are drawn to saying favorable things about formalism in the senses discussed so far. Formalism is used in a further sense, however, to refer to the application of the literal meaning of a linguistically clear and determinate rule, even when doing so produces results that are at odds with the purpose behind the rule. It is formalism in this last sense that has attracted qualified support from certain positivists. Fred Schauer, for example, remarks, "formalism of rules is not only conceptually sound and psychologically possible, but it also ... is on occasion normatively desirable" (19: p. 544). To describe his position, Schauer uses the term presumptive formalism," which, he suggests, is interchangeable with the term "presumptive positivism" (19: p. 548).

6. Russell's approach has attracted the support of other philosophers of sport, such as Robert L. Simon (24) and Nicholas Dixon (4).

7. The example of the UD shows that there is nothing essentially "just" about rule-based decision making (20: p. 137). In the circumstances of the UD, factors excluded from consideration by the rules (i.e., that the batsman must be out one way or another) turn out to be those necessary to reach the fair result.

8. 115 N.Y. 506, 22 N.E. 188 (1889).

9. By "intentions," we do not mean to refer to the mental states of the actual drafters. By "intentions" we mean the purpose and structure of the rules. It is possible to ascribe meaning to particular rules that makes sense of them as purposive communications; see Lon Fuller (10: pp. 82-91). The relevant intentions are, as T.R.S. Allan points out, "essentially metaphorical, since it does not belong to any particular author, whether draftsman or legislator" (1: p. 673). Such intentions are attributed to an ideal legislator, a device needed to "make the best sense we can of an historical event-someone or a social group with particular responsibilities, speaking or writing in a particular way on a particular occasion" (8: p. 1252).

10. It is of course true that law also deals with matters of lesser social significance: Laws relating to the conveyancing of property serve as examples. It is also true that sports might have serious social consequences. For example, it is possible to imagine a country going to war on the grounds of the result of a sporting event. In the latter case, however, the violent consequence is not mandated or required by the decision maker's ruling, whereas the serious consequences flowing from a judicial decision are those mandated or required by the decision itself. In law, decision makers mandate certain serious consequences such as death (in the United States), the removal of children from families, and so on. We do not think that the consequences of the decisions of sports decision makers are on the whole as serious - that, after all, is what makes games fun to play!

11. In cricket, the only resignation likely to have any impact would be that by an umpire in an international or otherwise high-profile match. In such a case, we must concede that it is at least possible that the public exposure would have the effect of forcing the decision-making body to confront this issue.

12. Law 3.6 allows for the change of umpire under "exceptional circumstances." 
13. We have faxed the England and Wales Cricket Board explaining the UD and suggesting that the rules be changed so that their literal meaning yields the fair result (fax dated January 13, 2006, on file with the authors).

\section{References}

1. Allan, T.R.S. "Legislative Supremacy and Legislative Intention: Interpretation, Meaning and Authority." Cambridge Law Journal. 63, 2004, 685-711.

2. Cover, R. Justice Accused: Antislavery and the Judicial Process. New Haven, CT: Yale University Press, 1975.

3. Cover, R. "Violence and the Word." Yale Law Journal. 95, 1986, 1601-1629.

4. Dixon, N. "Canadian Figure Skaters, French Judges, and Realism in Sport." Journal of the Philosophy of Sport. XXX, 2003, 103-116.

5. Dworkin, R. Taking Rights Seriously. London, UK: Duckworth, 1977.

6. Dworkin, R. Law's Empire. Cambridge, MA: Harvard University Press, 1986.

7. Dworkin, R. "Reflections on Fidelity." Fordham Law Review. 65, 1997, 1799-1818.

8. Dworkin, R. The Arduous Virtue of Fidelity: Originalism, Scalia, Tribe and Nerve." Fordham Law Review. 65, 1997, 1247-1268.

9. Feinberg, J. "Natural Law: The Dilemmas of Judges Who Must Interpret 'Immoral Laws." In: Problems at the Roots of Law, J. Feinberg. Oxford, UK: Oxford University Press, 2003, pp. 3-35.

10. Fuller, L. The Morality of Law. New Haven, CT: Yale University Press, 1969.

11. Hart, H.L.A. "Positivism and the Separation of Law and Morals." Harvard Law Review. 71, 1958, 593-629.

12. Hart, H.L.A. The Concept of Law. 2nd ed. Oxford, UK: Oxford University Press, 1994.

13. Lyons, D. Ethics and the Rule of Law. Cambridge, UK: Cambridge University Press, 1984.

14. MacCormick, N. Legal Reasoning and Legal Theory. Oxford, UK: Oxford University Press, 1978.

15. Oslear, D. Wisden: The Laws of Cricket. London, UK: Ebury Press, 2000.

16. Radford, C. "The Umpire's Dilemma." Analysis. 45, 1985, 109-111.

17. Russell, J.S. "The Concept of a Call in Baseball." Journal of the Philosophy of Sport. XXIV, 1997, 21-37.

18. Russell, J.S. “Are Rules All an Umpire Has to Work With?” Journal of the Philosophy of Sport. XXVI, 1999, 27-49.

19. Schauer, F. "Formalism." Yale Law Journal. 97, 1988, 509-548.

20. Schauer, F. Playing by the Rules: A Philosophical Examination of Rule-Based Decision-Making in Law and Life. Oxford, UK: Clarendon Press, 1991.

21. Schauer, F. "Constitutional Invocations." Fordham Law Review. 65, 1997, 12951312.

22. Shklar, J. Legalism: An Essay on Law, Morals and Politics. Cambridge, MA: Harvard University Press, 1964.

23. Silver, C. "Elmer's Case: A Legal Positivist Replies to Dworkin." Law and Philosophy. 6, 1987, 381-399.

24. Simon, R.L. "Internalism and Internal Values in Sport." Journal of the Philosophy of Sport. XXVII, 2000, 1-16.

25. Wacks, R. “Judges and Injustice.” South African Law Journal. 101, 1984, 266-285.

26. Waldron, J. Law and Disagreement. Oxford, UK: Clarendon Press, 1999. 
Copyright of Journal of the Philosophy of Sport is the property of Human Kinetics Publishers. Inc. and its content may not be copied or emailed to multiple sites or posted to a listserv without the copyright holder's express written permission. However, users may print, download, or email articles for individual use. 